\title{
Technologies and Practices of Linguistic and Sociocultural Adaptation of Foreign Students during Their Studies at the University
}

\author{
Lera A. Kamalova \\ Kazan (Volga region) Federal University, Russia \\ ORCID: 0000-0003-0260-7204 \\ Makhabbat Zh. Umbetova \\ Arkalyk State Pedagogical Institute, Kazakhstan \\ ORCID: 0000-0001-9844-2795 \\ Narine S. Putulyan \\ Kazan (Volga region) Federal University, Russia \\ ORCID: 0000-0002-4428-4143
}

Received: 2 Aug 2020

Accepted: 28 Oct 2020

\begin{abstract}
The aim of this work is to determine the most effective technologies and practices for the linguistic and sociocultural adaptation of foreign students studying in Russian and foreign universities, the use of which will help foreign students overcome barriers in academic performance, mastery of the Russian language, psychological and sociocultural adaptation in the host country. The fundamental basis of this study is the experimental work carried out at the Institute of Psychology and Education of Kazan Federal University, Arkalyk State Pedagogical Institute named after Y. Altynsarin, St. Petersburg National Research University of Information Technologies, Mechanics and Optics. Sociocultural and linguistic adaptation of foreign students is organized on the basis of an integrated approach, which is a combination of intercultural, humanistic, personality-oriented, activity-based approaches to learning. Education and training of foreign students should be organized on the basis of modern technologies and practices (authoring online simulators in Russian, interactive whiteboard, case method, brainstorming, role-playing game, discussion) contributes to effective language, socio-cultural adaptation of students. An effective tool to promote the sociocultural and linguistic adaptation of foreign students is a specially organized tolerant developing educational environment of the university, organized taking into account the specifics of social problems and the psychological state of migrants, contributing to the leveling of emerging problems of sociocultural adaptation, the integration of foreign students in the host community. In this study, the most effective diagnostics were identified that affect the mechanisms of linguistic and sociocultural adaptation of foreign students studying in Russian and foreign universities: diagnostics of the level of social isolation of a person, determination of the level of depression, methods for determining sociocultural identity, adaptation of a person to a new sociocultural environment, methodology for determining level of knowledge of Russian as a foreign language. The scientific novelty of this study is to determine the most effective technologies and practices of linguistic and sociocultural adaptation of foreign students in the context of globalization and the Eurasian integration of sociocultural and educational space.
\end{abstract}

Keywords: foreign students, migrants, adaptation, linguistic, sociocultural, technology, pedagogical, learning, Russian 


\section{INTRODUCTION}

The relevance of a research is caused by migration processes in Russia and foreign countries, big inflow to Russia and other countries of the foreign students who chose higher education institution, the university which is in other state as receiving the higher education (Bąk et al., 2019; Bayanova et al., 2019). In such a case, foreign students experience a number of difficulties related to language, sociocultural and psychological adaptation in the receiving country.

The most important problem for foreign students is mastering the language of the receiving country. For foreign students studying in Russia, mastering Russian is a great difficulty (Gvarliani, Vidishcheva, \& Rassolov, 2015; Khairullina et al., 2020; Kurkimbayeva et al., 2020). Another factor causing difficulties in the process of education of foreign students is the difference in the methods and techniques of study that are accepted in certain universities. In order to successfully adapt students to the methods and techniques of study, it is important to summarize the positive experience of universities hosting foreigners. Most often, in foreign countries, student education uses interactive learning technologies aimed at active interaction of students with each other and the teacher, as well as learning based on digital educational technologies. While Russian universities mostly use traditional teaching methods: lecture, seminar, workshop, laboratory work. The study of foreign students at the university requires the use of a wide variety of modern technologies, methods, practices for successful linguistic, sociocultural adaptation of students, as this directly affects the academic adaptation and success of students, the possibility of professional development and development (Masalimova et al., 2018; Zyubina et al., 2019). The education of foreign students at the university dictates another necessity - an appeal to the context of multicultural education, which contributes to the learning of foreign students about other cultures, understanding of common and different in traditions, way of life, sociocultural values of other peoples (Gorbunov et al., 2019).

\section{LITERATURE REVIEW}

\section{Condition of Readiness of a Problem}

The concept of multicultural education and the organization of multicultural educational space is revealed in the studies of Gukalenko (2003), Bondarevskaya (1999), Banks (1996), Nieto (1996).

Features of sociocultural adaptation of studying migrants were studied by Bondarenko et al. (2007), Palatkin (2001), Bondyreva (2011), Zasipkin, Zborowski, and Shuklina (2012), and Dyzhakova (2008).

Works of Antipiev (2009), Akhtarieva, Ibragimova, and Puchinina (2019), Beregovaya, Lopatina, and Oturgasheva (2019), and Koslovtseva and Tolstova (2019) are devoted to some aspects of the adaptation of Foreign Students.

Kamalov's (2015) scientists, Chubko et al. (2019), Meng, Zhu, and Cao (2018), Kim, Kim, and Kim (2019), Zhou, Zhao, and Dawson (2020), and Santillan et al. (2018) write about a technique of language adaptation of foreign students and practice of training in Russian the foreign students.

Researchers Slastenin et al. (2002) write about traditional methods and techniques of teaching and technology of interactive training.

In spite of the studies available in the field of linguistic, intercultural and sociocultural adaptation of foreign students, important aspects of the use of educational technologies, methods and practices in the education of foreign students in higher education, which would have an effective impact on the linguistic and sociocultural adaptation of students in the country of admission, remain undeveloped. The problem of studying the relationship between language proficiency and the degree of sociocultural integration of foreign students is also insufficiently developed. 


\section{Review of Russian Academic Literature}

Gukalenko (2003) has proposed certain methods and forms of pedagogy of work with migrants, combination of general medical with specific (monitoring, diagnostics, pedagogical modeling, stimulation of interest and involvement in activities, assistance and creativity). When developing a meaningful characteristic of specific methods, the age and individual characteristics of the student should be taken into account; The specificity of intercultural communication between migrant children and peers and adults; The capacity of the educational institution and the teacher to provide specific assistance to migrants in their support for intercultural adaptation.

Bondarevskaya (1999) considers multicultural education as a pedagogically managed process of cultural identification, social adaptation and creative self-realization of the individual, during which the child enters the world of culture, into the life of society.

Bondarenko et al. (2007) study the phenomenon of education as a factor in the approval in society of norms of ethno-religious tolerance in the context of globalization. According to scientists, in order to promote tolerance among young people and children, it is necessary to develop various forms of organization of the educational process as discussion, inter-group dialogue, social and projective activities, solution of issues of child health protection, organization of leisure time, access of young people to culture, sports activities. And in the sphere of inter-ethnic relations - promotion of dialogue of various cultural traditions, deconstruction and demiphologization of biased images of the Other, opposition to the spread of ethno- and migrantphobias.

Zasypkin, Zborovsky, and Shuklin (2012) consider problems of linguistic and sociocultural adaptation of migrant children, formation of inter-ethnic tolerance in conditions of education in general education school.

Scientists consider the peculiarities of multicultural education and define it as "an education that creates equal opportunities for all ethnic groups to realize their cultural needs, which involves young people in the cultural and moral values of other countries and peoples." It is in multicultural education that the principle of dialogue and interaction between cultures is fully realized (Zpypkin, Zborovsky, \& Shuklin, 2012).

Palatkina (2001) believes that multicultural education is a preparation for life in a multi-ethnic society: mastery of the culture of his people, creation of ideas about diversity of cultures and education of ethnotolerance.

Russian scientists emphasize the specificity of multicultural education methods, which is determined by the dialogue nature of the functioning and development of culture, the level of ethnocultural identification of the student, the level of knowledge of the students about the multicultural environment, their emotional and behavioural culture, which requires the use of active teaching methods: dialogue, conversation, discussion, modeling, design, reconstruction, role-playing games, reflexive methods (Palatkina, 2001).

Domestic scientists recommend to organize classes with students on small and large creative groups; Group tasks are performed in such a way that allows to take into account and evaluate individual contribution of each member of the group (Slastenin et al., 2002).

One of the main challenges faced by migrants in developing a new place of residence is sociocultural adaptation, which is a complex, multidimensional and often lengthy process involving migrants experiencing change, cultural differences, exclusion and deprivation.

Bondyreva (2011) notes that "in the new place of residence the migrant will have to withstand a great adaptive burden: to establish many new ties; To develop an assessment of new objects, processes, phenomena. Immigrant children will have to reassess much of their past experience; Establish life-friendly relationships with new people and develop a certain attitude in general towards the realities of new life; Develop new life habits" (Bondyreva, 2011).

According to Duzhakova (2008), adaptation in the educational environment is the foundation for migrant students to adapt to a new place of residence, which is determined by the diversity of their functions and the 
potential that ensures the integration of the child at all educational levels (3). Sociocultural adaptation is a process determined by the ratio of sociocultural environment to personal psychological and ethnocultural features (Dyuzhakova, 2008).

According to Antipiev (2009), sociocultural adaptation is a form of interaction of the subject with the sphere of everyday life, creating conditions for the subject to effectively enter into society and develop various forms of social activity. Its content is the mastering of new, non-standard situations in everyday life, and the result is mutual cooperation, compatibility and exchange of products of the activity of the individual and the environment.

Akhtarieva, Ibragimova, and Puchinina (2019) studied the dynamics of shaping the professional intercultural competence of future teachers in foreign students. The diagnosis of the general level of tolerance among the surveyed students, types of ethnic identity and positive ethnic identity shows the formed professional intercultural competence of future teachers in foreign students living in Russia from 0 to 5 years.

Authors Beregovaya, Lopatina, and Oturgasheva (2019) exploring barriers to sociocultural adaptation of foreign students, concluded that the main barrier to successful sociocultural adaptation of foreign students is the language barrier, which significantly affects overcoming other barriers -cross-cultural and academic.

Kozlovtseva and Tolstova (2019) explores the formation of the image of the Russian world as an aspect of the sociocultural adaptation of foreigners in the process of teaching Russian. Scientists write about the important role of preparatory faculties, where purposeful and systematic work is carried out on sociocultural adaptation of foreign citizens through the current image of the Russian world, the basic design of which is Russian.

In the learning process interactive technologies allow teachers to create a special learning environment, design training situation creatively, ensuring increase the activity of students in the acquisition of knowledge and skills, create conditions for the formation of professional competence of future specialists of primary education (Kamalova, 2015).

\section{Review of International Academic Literature}

The writings of foreign scholars Banks (1996), Nieto (1996) substantiate that the historical diversity of national and ethnic cultures creates positive conditions for the development of multicultural education and pedagogical support for migrant children in a multicultural society.

Foreign scientists note that the modern world is a world of globalization. The processes of globalization require not only a further significant increase in the "general level of education of the population and at the same time the growth of a whole social layer of people able to work effectively in the most modern knowledge and information-intensive industries," but also "a strong introduction of the principles of tolerance into the consciousness of students" (Nieto, 1996).

Tolerance today is recognized by leading scientists as a social and professional value, which is an important and integral element of the social competences of the individual. As foreign researchers stress, "the strategy of tolerance formation can be effective only if it covers the main spheres of human socialization and development of social competences, includes a whole set of various program measures"(Banks, 1996).

Authors Chubko et al. (2019) note that better psychological adaptation is seen in women, older students and those more satisfied with their social lives in the host country. Participants who have better adapted socially and culturally also belong to the older age group, are more satisfied with their social situation, have demonstrated a higher orientation towards Croatia and believe that the culture of their host countries is more like their home culture.

Meng, Zhu, and Cao (2018) conducted a study on the interrelationship of linguistic, sociocultural and academic adaptation of foreign students and concluded that proficiency in English and local languages was an important predictor of the global competence of Chinese students in Belgium, and global competence in turn significantly influenced the social connectivity of participants, social and academic adaptation. 
Kim, Kim, and Kim (2019) studied influence of stability on motivation and knowledge of the second language among pupils of elementary school in South Korea. It has been revealed that sustainability consists of metacognitive adaptation, sociability, optimism, perseverance and communicative efficiency. In terms of the impact of sustainability, SEM imagines that the direct impact of sustainability on the motivation of learning English as a foreign language (EFL) is greater than its effect on demotivation.

Zhou, Zhao, and Dawson (2020) investigated the dependence of academic literacy of first-year Chinese students on their knowledge of and possession of English as a foreign language. The results of the study show that increasing academic literacy of students includes both language development and epistemological adaptation.

Santillan et al. (2018) studied language problems and cultural adaptation of foreign students at a major private university in the Philippines. The authors measured the adaptation of foreign students to a sociocultural and educational environment in terms of four dimensions: cultural empathy, unbiased attitude, emotional stability and social flexibility. The results showed that cultural empathy and unbiased were negatively correlated with length of stay, while flexibility was positively correlated with length of stay.

\section{MATERIALS AND METHODS}

To test the hypothesis, a set of different methods was used, complementary to each other: theoretical analysis of the works of teachers and psychologists on the problem of research; Analysis of methodological and educational literature; Theoretical analysis of the main provisions of the proposed methodology, on the basis of which the study hypothesis is put forward; Theoretical justification of the study problem; Empirical included observation, stating and forming pedagogical experiment, questionnaire, testing, analysis of results of experimental work.

\section{Base of a Research}

Experimental research base - Institute of Psychology and Education of Kazan Federal University (Russia); Arkalyk State Pedagogical Institute named after Y. Aaltynsarin (Kazakhstan); St. Petersburg National Research University of Information Technologies, Mechanics and Optics (Russia).

180 foreign students took part in experimental work: 90 people - experimental group (students of the Institute of Psychology and Education of KFU - 37 people. And Arkalyk State Pedagogical Institute named after Y. Aaltynsarin - 53 persons); 90 persons - control group (students of St. Petersburg National Research University of Information Technologies, Mechanics and Optics). The experiment was conducted in the 20192020 academic year.

\section{Investigation Phases}

The study was conducted in three stages:

At the first stage, an experimental platform was created on the basis of the Institute of Psychology and Education of KFU, the Arkalyk State Pedagogical Institute named after Y. Aaltynsarin, the St. Petersburg National Research University of Information Technologies, Mechanics and Optics (ITMO University), the process of training, adaptation of foreign students was monitored, the topic of the study was tested at the initial stage of the experiment.

At the second stage, the concept of the study was clarified and adjusted, an educational experiment was conducted among foreign students of the Institute of Psychology and Education of KFU, Arkalyk State Pedagogical Institute named after Y. Aaltynsarin.

In the third stage, the analysis, synthesis and systematization of the obtained data was carried out, the study was prepared; The subject of the study was tested in the author 's publications and speeches at scientific conferences. 
Table 1. Adapting Personality to a New Sociocultural Environment (Yankovsky, 2005) in an Experimental Group

\begin{tabular}{|c|c|c|c|c|c|c|}
\hline $\begin{array}{l}\text { Manifestation } \\
\text { levels }\end{array}$ & $\begin{array}{c}\text { Adaptability } \\
\text { scale }\end{array}$ & $\begin{array}{c}\text { Conformality } \\
\text { scale }\end{array}$ & $\begin{array}{c}\text { Interactivity } \\
\text { scale }\end{array}$ & $\begin{array}{c}\text { Depressiveness } \\
\text { scale }\end{array}$ & Nostalgia scale & $\begin{array}{c}\text { Estrangement } \\
\text { scale } \\
\end{array}$ \\
\hline High & $34 p p l$ & $23 p p l$ & $24 p p l$ & $37 p p l$ & $36 p p l$ & $16 p p l$ \\
\hline Average & $38 \mathrm{ppl}$ & 31ppl & $29 p p l$ & $39 p p l$ & $38 \mathrm{ppl}$ & 30ppl \\
\hline Low & $18 \mathrm{ppl}$ & $36 \mathrm{ppl}$ & $37 p p l$ & $14 \mathrm{ppl}$ & $16 \mathrm{ppl}$ & $44 \mathrm{ppl}$ \\
\hline
\end{tabular}

Table 2. Adaptation of personality to the new sociocultural environment (Yankovsky, 2005) in the Control Group

\begin{tabular}{|c|c|c|c|c|c|c|}
\hline $\begin{array}{l}\text { Manifestation } \\
\text { levels }\end{array}$ & $\begin{array}{c}\text { Adaptability } \\
\text { scale }\end{array}$ & $\begin{array}{c}\text { Conformality } \\
\text { scale }\end{array}$ & $\begin{array}{c}\text { Interactivity } \\
\text { scale }\end{array}$ & $\begin{array}{c}\text { Depressiveness } \\
\text { scale }\end{array}$ & Nostalgia scale & $\begin{array}{c}\text { Estrangement } \\
\text { scale }\end{array}$ \\
\hline High & $37 p p l$ & $22 \mathrm{ppl}$ & $22 \mathrm{ppl}$ & 39ppl & $37 p p l$ & $28 p p l$ \\
\hline Average & $34 p p l$ & 33ppl & 27ppl & $38 p p l$ & $38 \mathrm{ppl}$ & $38 p p l$ \\
\hline Low & 19ppl & $36 \mathrm{ppl}$ & 41ppl & 13ppl & $15 \mathrm{ppl}$ & $31 \mathrm{ppl}$ \\
\hline
\end{tabular}

Table 3. Methodology for Determining Sociocultural Identity (Pocebut,2005)in an Experimental Group

\begin{tabular}{lccc}
\hline Result & Sociocultural identity & Regional identity & Racism \\
\hline Positive & $41 \mathrm{ppl}$ & $47 \mathrm{ppl}$ & $5 \mathrm{ppl}$ \\
Negative & $49 \mathrm{ppl}$ & $43 \mathrm{ppl}$ & $85 \mathrm{ppl}$ \\
\hline
\end{tabular}

Table 4. Methodology for determining sociocultural identity (Pocebut,2005) in the Control Group

\begin{tabular}{lccc}
\hline Result & Sociocultural identity & Regional identity & Racism \\
\hline Positive & $33 p \mathrm{pl}$ & $35 \mathrm{ppl}$ & $7 \mathrm{ppl}$ \\
Negative & $57 \mathrm{ppl}$ & $55 \mathrm{ppl}$ & $83 \mathrm{ppl}$ \\
\hline
\end{tabular}

Table 5. Determination of the level of depression of T.I. Balashov (2006) in the Experimental Group

\begin{tabular}{lccc}
\hline $\begin{array}{l}\text { Condition without } \\
\text { depression (no more than } \\
50 \text { points) }\end{array}$ & $\begin{array}{c}\text { Condition of mild depression } \\
\text { (more than 50, but not less } \\
\text { than } 59 \text { points) }\end{array}$ & $\begin{array}{c}\text { Subdepressive state (60 to } \\
69 \text { points) }\end{array}$ & $\begin{array}{c}\text { True depressive state (more } \\
\text { than } 70 \text { points ) }\end{array}$ \\
\hline $20 \mathrm{ppl}$ & $31 \mathrm{ppl}$ & $37 \mathrm{ppl}$ & $2 \mathrm{ppl}$ \\
\hline
\end{tabular}

\section{RESULTS}

\section{Progress and Description of the Reporting Stage of the Experiment}

At the stage of the stating experiment, a questionnaire was conducted on diagnostics "Adaptation of personality to a new sociocultural environment" (Yankovsky, 2005); Methodology for determining sociocultural identity (Pocebut,2005); Diagnosis “Determination of depression level» (Balashov, 2006);Testing on "Express diagnostics of the level of social isolation of the individual"(Fetiskin, Kozlov, \& Manuylov, 2002); "Methodology for determining the level of knowledge of Russian as a foreign language" (Sherina, 2013; Jarica, 1977).

The results of the method of adaptation of personality to the new sociocultural environment in experimental and control groups show belonging to 6 types of adaptation, demonstrate: High level of adaptability, conformity, interactivity (38\%, 26\%, 25\% - experimental group, $41 \%, 23 \%$, $24 \%$ - control group) and at the same time high level of depression, nostalgia, alienation (41\%, 40\%, 17\% - experimental group, 43\%, 39\%, $23 \%$ - control group). It is possible to conclude that both groups are at the same level of adaptation to the new environment.

Thus, the results of the diagnosis of the definition of sociocultural identity showed: Sociocultural identity from 22 to 50 - positive result -33 people; 51 to 88 - negative result - 57 people Regional identity - from 6 to 15 - positive result -35 people, from 16 to 24 - negative result 55 people. Rasizm- from 26 to 32 - positive result - 7 people; From 8 to 25 - negative result - 83 people. 
Table 6. Determination of the level of depression of T.I. Balashov (2006) in the Control Group

Condition without depression (no more than 50 points)
Condition of mild depression

(more than 50, but not less than 59 points)
Subdepressive state (60 to True depressive state (more 69 points) than 70 points )

$18 \mathrm{ppl}$ $33 p p l$ $36 \mathrm{ppl}$ $3 p p l$

Table 7. Express diagnosis of the level of social isolation of the individual (D. Russell and M. Fergusson) in the Experimental Group (Fetiskin, Kozlov, \& Manuylov, 2002)

\begin{tabular}{lccc}
\hline $\begin{array}{l}\text { Level of expressiveness of } \\
\text { sign }\end{array}$ & $\begin{array}{c}\text { High degree of personal } \\
\text { isolation (41 to } 60 \text { points) }\end{array}$ & $\begin{array}{c}\text { Average degree of personal } \\
\text { isolation (21 to } 40 \text { points) }\end{array}$ & $\begin{array}{c}\text { Low degree of personal } \\
\text { isolation (0 to 20 points) }\end{array}$ \\
\hline $\begin{array}{l}\text { High } \\
\begin{array}{l}\text { Average } \\
\text { Low }\end{array}\end{array}$ & $30 \mathrm{ppl}$ & $38 \mathrm{ppl}$ & $22 \mathrm{ppl}$ \\
\hline
\end{tabular}

Table 8. Express diagnosis of the level of social isolation of the individual (D. Russell and M. Fergusson) in the Control Group (Fetiskin, Kozlov, \& Manuylov, 2002)

\begin{tabular}{lccc}
\hline $\begin{array}{l}\text { Level of expressiveness of } \\
\text { sign }\end{array}$ & $\begin{array}{c}\text { High degree of personal } \\
\text { isolation (41 to } 60 \text { points) }\end{array}$ & $\begin{array}{c}\text { Average degree of personal } \\
\text { isolation (21 to } 40 \text { points) }\end{array}$ & $\begin{array}{c}\text { Low degree of personal } \\
\text { isolation (0 to 20 points) }\end{array}$ \\
\hline $\begin{array}{l}\text { High } \\
\begin{array}{l}\text { Average } \\
\text { Low }\end{array}\end{array}$ & $32 \mathrm{ppl}$ & $34 \mathrm{ppl}$ & $24 \mathrm{ppl}$ \\
\hline
\end{tabular}

Table 9. Level of definition of Russian language proficiency as foreign language (Jarica, 1977; Sherina, 2013) in Experimental Group

\begin{tabular}{lccccc}
\hline $\begin{array}{l}\text { Basic language } \\
\text { proficiency (A1) }\end{array}$ & $\begin{array}{c}\text { Basic language } \\
\text { proficiency (A2) }\end{array}$ & $\begin{array}{c}\text { Independent } \\
\text { possession (B1) }\end{array}$ & $\begin{array}{c}\text { Independent } \\
\text { possession (B2) }\end{array}$ & $\begin{array}{c}\text { Free possession } \\
\text { (C1) }\end{array}$ & $\begin{array}{c}\text { Free possession } \\
\text { (C2) }\end{array}$ \\
\hline $34 \mathrm{ppl}$ & $45 \mathrm{ppl}$ & $11 \mathrm{ppl}$ & $0 \mathrm{ppl}$ & $0 \mathrm{ppl}$ & $0 \mathrm{ppl}$ \\
\hline
\end{tabular}

Table 10. Level of definition of Russian language proficiency as foreign language (Sherina, 2013; Jarica, 1977) in the Control Group

\begin{tabular}{lccccc}
\hline $\begin{array}{l}\text { Basic language } \\
\text { proficiency (A1) }\end{array}$ & $\begin{array}{c}\text { Basic language } \\
\text { proficiency (A2) }\end{array}$ & $\begin{array}{c}\text { Independent } \\
\text { possession (B1) }\end{array}$ & $\begin{array}{c}\text { Independent } \\
\text { possession (B2) }\end{array}$ & $\begin{array}{c}\text { Free possession } \\
\text { (C1) }\end{array}$ & $\begin{array}{c}\text { Free possession } \\
\text { (C2) }\end{array}$ \\
\hline $29 \mathrm{ppl}$ & $36 \mathrm{ppl}$ & $5 \mathrm{ppl}$ & $0 \mathrm{ppl}$ & $0 \mathrm{ppl}$ & $0 \mathrm{ppl}$ \\
\hline
\end{tabular}

Depression levels range from 20 to 80 points. If the level of depression is not more than 50 points, the condition without depression is diagnosed. If the level of depression is more than 50 points, but less than 59 , a conclusion is made about mild depression of situational or neurotic genesis. If the depression level is 60 to 69 points, a subdepressive condition or disguised depression is diagnosed. A true depressive condition is diagnosed at a depression level of more than 70 points.

The results of rapid diagnostics of the level of social isolation of personality (D. Russell and M. Fergusson) in experimental and control groups showed a high degree of isolation in both groups - $33 \%$ and $35 \%$, average degree $-42 \%$ and $37 \%$, low degree $-24 \%$ and $26 \%$.

The method of determining the level of proficiency in Russian as a foreign language was used Sherina (2013) methodology, Jarica (1977). The level diagram is based on the principle of sequential branching. It begins by dividing the level system into three major levels: elementary proficiency in language (A), self-proficiency (B), fluency (C). A1 - "I understand and can use in speech familiar phrases and expressions necessary for carrying out specific tasks. I can introduce myself/introduce others, ask/answer questions about place of residence, friends, property. I can participate in a simple conversation if the speaker speaks slowly and clearly and is ready to assist. " A2 - "I understand individual sentences and common expressions related to the main spheres of life (for example, basic information about myself and family members, purchases, work arrangements, etc.). I can perform tasks related to the simple exchange of information on familiar or household topics. In simple terms I can tell about myself, my relatives and relatives, describe the main aspects 
of everyday life. "B1 - "I understand the basic ideas of clear messages made in the literary language on different topics, typically arising at work, study, leisure, etc. I am able to communicate in most situations that may arise during the stay in the country of the language being studied. I can compose a coherent message on known or particularly interesting topics. I can describe impressions, events, hopes, aspirations, present and settle my opinion and plans for the future. "B2 - "I understand the general content of complex texts on abstract and specific topics. I speak quickly and spontaneously enough to constantly communicate with the speakers of the language without much difficulty for either side. I am able to make clear, detailed messages on various topics and to present my view on the main problem, to show the advantage and shortcomings of different opinions. " C1 - "I understand voluminous complex texts on different topics, I recognize hidden value. I speak spontaneously at a rapid pace, without having difficulty selecting words and expressions. I use language flexibly and effectively to communicate in scientific and professional activities. I can create an accurate, detailed, well-structured message on complex topics, demonstrating ownership of text organization models, communication tools and the integration of its elements. " C2 - "I understand almost any oral or written communication, I can draw up a coherent text based on several oral and written sources. I speak spontaneously with a high tempo and a high degree of accuracy, emphasizing shades of values even in the most difficult cases."

The results of the diagnosis on the level of proficiency in Russian showed that the experimental and control groups speak the language at the initial level: A1 - 37\% and 32\%, A2 - 50\% and 40\%, B1 - $1.8 \%$ and $0.5 \%$. There are no foreign students in both groups who speak Russian at the B2 level, C1, C2.

\section{Course and Description of the Forming Stage of the Experiment}

At a stage of the forming experiment in experimental group of foreign students 1 and 3 courses (90 people) studying lecture, seminar, laboratory classes with use of different technologies of training were given in the Pedagogical education direction of the Primary education profile: "brainstorming", a case method, roleplaying games, were actively used the interactive board, author's online simulators for Russian placed on the educational Online Test Pad platform.

The method of "brainstorming" as an operational method of a solution on the basis of stimulation of creative activity gives the chance to state as the bigger quantity of versions of the decision including original is possible. At the classes on pedagogy with the students of the 1 course there was held a practical lesson by the method of brainstorming, consisting of stages: presentation of a problem, generation of ideas, grouping, selection and evaluation of ideas, summing up of results. During the brainstorming, students expressed their ideas aimed at solving the task. From the total number of ideas expressed, the most successful ones were selected, which could be used in practice.

The "brainstorming" technique is an active form of student education, a set of methods and techniques of collective solution of the problem on the basis of stimulation of creative activity, in which participants of discussions are invited to express as many solutions as possible. The result of the application is to solve complex problems (situations) by applying special rules of discussion and generating new ideas on possible options for the process. At the seminar classes on children 's literature with foreign students there were "brain attacks" on the topics "Peculiarities of children 's literature of 20-30," Peculiarities of children 's literature of 40-50, "Peculiarities of children 's literature of 60-80."

Case-stages as a method of study contribute to the formation of the ability of foreign students to make decisions first in similar and then in non-standard specific socio-cultural situations. When working with a case, students form such components of key competences as: ability to solve problems, sociability, apply substantive knowledge in practice, ability to negotiate, take responsibility and express their position, tolerance, reflexive skills, carry out analysis and diagnostics of problems.

The case-stage method is based on interactive interaction between teachers and students, it gives future workers in the social and cultural sphere the opportunity to show initiative, autonomy in decision-making, promotes the acquisition of practical skills, methods of social and cultural activity, i.e. makes a significant 
contribution to the formation of their social competence. Practical classes with foreign students on case herd technology were held on the course "Methodology of teaching literary reading in primary school."

The role-playing game was actively used by us in the courses "Children 's Literature," Pedagogical Rhetoric "to form the linguistic and sociocultural competence of students. In the process of role-playing, the skills of students are closely and actively connected with the sociocultural reality of the language being studied with the direct participation of the teacher, the use of textbooks, as well as other means of teaching. The activation of students 'activities in the process of role-playing is ensured by the use of technical means. At the present stage, students widely use the Power Point program and remote projection system during their speech, which makes this process more fascinating and creative for communicants, as well as more attractive and visible for listeners.

In addition, situation descriptions, instructions and, crucially, long and thorough language training are used to create the role situations upon which games are organized and played, some of which are role-based. Built on this principle, role play stimulates the speech activities of students, contributing to the formation of stronger skills and skills. Role play forms the ability of students to play the role of another person, to see themselves from the position of a communication partner. It guides students to plan their own speech behavior and the behavior of the interviewer, develops the ability to control their actions, give an objective assessment of the actions of others. Therefore, role play can be considered as the most accurate model of communication, because it implies imitation of reality in its most significant features. The important thing is that in role-playing games, the speech and non-speech behavior of partners is intertwined in the closest way. Therefore, role play can be called a form of imitation simulation of conditions of future professional activity, in the process of implementation of which students develop and then improve vocational-oriented skills. We played role games in the form of a literary trial of the hero of the work "Literary Trial of Glodnulya" (according to the fairy tale "Moidodyr"). Work is organized in groups: prosecution, defence, independent experts. In such a lesson there is a search for evidence and evidence. The members of the groups discuss the points that seem to them most convincing, stressing and proving their right. It is important for us to guide the work of each group in the right direction. Each student as a participant of the future process makes a plan of his speech, prepares questions for opponents. The role of the teacher at this stage is limited to counselling.

For the purpose of linguistic and sociocultural adaptation of foreign students, we used interactive learning technologies. Interactive technologies that combine the ability to simultaneously obtain an image of an object, a process in various information representations: graphics, sound, video, and implementation of motion dynamism, transformation of objects in the form of animation, which increases the efficiency of education of foreign students.

We used the following forms of information technologies in classes with foreign students at the course "Russian Language":

1) creation of computer presentations by the teacher and student;

2) work with Russian language sites;

3) use of electronic dictionaries and encyclopedias;

4) performing tasks of students with audio and video materials from the Internet;

5) language training through ESM and COR, created by the teacher on the site of the educational institution.

Use on classes in Russian of an interactive board allows to show slides, video, to do marks, to draw, draw various schemes as on a usual board, in real time to apply on the projected image of a mark, to make any changes and to keep them in the form of computer files for further editing, the press on the printer, mailings by the fax or e-mail. Working online with the interactive board allows students to work independently with various sources of information, including the Internet. The interactive board allows for interactive communication with students. The technological capabilities of the interactive board allow the teacher to 
prepare a lesson note on a computer, store it in digital form, include the necessary visual material (presentations, photos, drawings, audio and video fragments, links to Internet resources, etc.).

During the forming experiment, the classes on the course "Russian Language" used author 's online Russian language simulators, created by us for foreign students studying Russian, and include the following sections: phonetics, word formation, morphology, morphemics, development of coherent speech. Each section of the online simulator consists of a test that includes 30 questions. Every foreign student who has registered on the Online Test Pad platform can study on this online simulator. After each question and answer, the correct answer is highlighted. After passing online surveys, the total number of points collected is counted.

\section{Progress and Description of the Control Phase of the Experiment}

At the control stage of the experiment, diagnostic sections on the same methods were carried out to determine the level and dynamics of linguistic and sociocultural adaptation of foreign students during their studies at the university as at the stating stage of the experiment. The data of the control section showed changes in comparison with the measurements of the stating experiment for all criteria, but these changes were significant only in the experimental group, where there was a shift in the number of students with medium and high levels of linguistic and sociocultural adaptation.

The diagnosis of "Adaptation of Personality to a New Sociocultural Environment" (Yankovsky (2005) Test) by the School of Adaptability showed that for foreign students of the experimental group the sense of social and physical protection became important (67\%); A sense of belonging to and belonging to a given society (73\%). Most students in this group are characterized by a desire for self-realization (67\%); Positive attitude towards others (78\%); high level of activity (76\%); Confidence in relations with others (75\%); Planning for your future based on your own capabilities (69\%). On the conformity scale, foreign students of the experimental group showed positive changes in their desire to maintain relations with people under all conditions (87\%); Orientation towards social approval (76\%); Group dependency (67\%); The need for affection and emotional relationships with people (79\%); Adoption of a system of values and norms of behaviour of the environment (75\%). On the scale of interactivity foreign students of the experimental group demonstrated: acceptance of this environment (77\%); Commitment to expanding social ties (80\%); A sense of confidence (78\%); Criticality to self-conduct (79\%); Self-conversion readiness $(76 \%)$; The desire to realize itself by achieving material independence (74\%); Focus on cooperation with other students (76\%); Control over own behaviour, taking into account social norms, roles and social attitudes of the society in question (79\%). Results on the depression scale showed that the control group had a high depression rate (65\%). Such migrants are characterized by reduced self-esteem (79\%); Helplessness to life (67\%); Inability to realize social and professional expectations (75\%); Anxiety about social identity (65\%); Unrealignment of own abilities associated with rejection of oneself and others (68\%); Feeling depressed, devastated, isolated (69\%). On the nostalgia scale, the control group showed good results, which means loss of association with the culture, ownership with it (56\%); Internal disorder and confusion due to a sense of disconnect with traditional values and standards and the inability to find new ones (76\%). On the scale of alienation, diagnostics showed a high level of alienation of the control group: rejection of the new society $(69 \%)$; low self-assessment $(59 \%)$; Inconsistency of personal claims and real possibilities (68\%); Concern about identity and status (63\%); Influence of external control on general rejection of itself and others (64\%).

The "Methodology for Determining Sociocultural Identity" (OSCI) shows that the experimental group has gained fewer balls for each of the three schools (sociocultural identity, regional identity, racism), which confirms our hypothesis foreign students of the group are aware of their sociocultural and regional identity, and have no racist tendencies. Diagnosis "Determination of depression level Balashov (2006)" demonstrated in students of experimental group condition without depression - $89 \%$, condition of mild depression - $10 \%$, subdepressive condition - $1 \%$. The results of the rapid diagnosis of the level of social isolation of the person (D. Russell and M. Fergusson) showed that in the experimental group there was a low degree of social isolation (1\%), while in the control group it was: a high degree of isolation $-64 \%$, an average degree $-25 \%$, a low degree $-11 \%$. Diagnostics of the definition of the level of proficiency in Russian as a foreign language 
showed that in the experimental group the language adaptation and mastery of the norms and rules of Russian language went much faster and more effectively than in the control group.

\section{DISCUSSIONS AND CONCLUSION}

Socio-cultural adaptation is a continuous and gradual process. Researchers identify several steps in this process. Preventive stage. At this stage, the student gets acquainted with the educational organization through the Internet, representatives of the university, students studying at this university. Targeted work is carried out among students of the 2nd year who plan to continue their studies in higher education. One important area is the acquisition of pedagogical terminology by students, which contributes to their understanding of the organization of the education system. The mastery of pedagogical terminology contributes not only to the more successful mastering by foreign students of theoretical disciplines "Psychology," Pedagogy, "Methodology of teaching Russian as a foreign language," i.e. to overcome the didactic barrier, but also to the inclusion of students in the educational space of the university, and in the future - to the rapid passage of industrial practice. 2. Initial stage (first two months of stay). At this stage, the student begins entering the educational environment of the university, which is implemented as part of its inclusion in the broad sociocultural environment, assistance is provided to students in sociocultural adaptation, which is of a systemic nature. In summer (July-August), after entrance examinations and university enrollment, study tours of the university and the city are organized.

At the same time, classes in Russian are held, where students learn the vocabulary and grammatical designs necessary for comfortable stay at university and for correct selection of speech behavior models in different situations of interaction in the course of education. At the initial stage of sociocultural adaptation the first familiarity of foreign students with culture takes place, the student makes the first attempts to speak Russian with its carriers, faces the first difficulties of intercultural dialogue. Problems are evident here, which are inevitable for a foreign student caught in new conditions. Students may have cultural shock -emotional or physical discomfort caused by getting into a different cultural environment, colliding with a different culture, an unfamiliar place. At this time, the university faces a serious task - to give such information about the city, about the university, which would allow the student to feel comfortable in the new language and cultural environment and, as a result, would make the student attractive to study in the Russian university, create a positive motivation of study. Teachers, curators come to help students, who need to know the nationalcultural peculiarities of students in order to correctly understand the causes of cultural shock and successfully overcome it. In recent years, tutor support technologies have been increasingly used, which allow to implement an individual approach in the socio-cultural adaptation of foreign students. The main stage (continues all the time of study of the student in the university). At this stage, the provision on the need to transfer to foreign students knowledge about the value and regulatory system of Russian culture, the degree of assignment of which depends on the effectiveness of sociocultural adaptation to the conditions of study in the Russian university, is particularly relevant.

For successful socio-cultural adaptation of foreign students various events are held, within the framework of which students can learn about traditions of our country and university. Among the most important events are familiarization with the history of the university, holding competitions and Olympiads in the Russian language, concerts where foreign students can fully reveal their creative abilities. The presentation of national holidays, Days of national cultures by students of the native country plays a special role. The University for the Education of Foreign Citizens holds a series of similar events, which have become traditional. At the same time, students, presenting their culture, better learn Russian culture, including its peculiarities, which are necessary for successful sociocultural adaptation to the conditions of study in the university.

The leading approach in carrying out the study was an integrated approach, which is a set of intercultural, humanistic, personal-oriented, activity-oriented approaches. An effective tool for promoting the sociopsychological and linguistic adaptation of foreign students is a specially organized tolerant educational environment, organized taking into account the specific social problems and psychological condition of migrants, which contributes to the levelling of emerging problems of sociocultural adaptation, integration of 
foreign students into the host community, as well as problems related to the formation of identity in another sociocultural environment. In order to organize linguistic and sociocultural adaptation of foreign students during our studies at the university, we have developed methodological recommendations addressed to students, parents and teachers.

Teachers: It is necessary to create the most favorable conditions for the disclosure and development of the abilities of each student, the formation of a harmonious personality turned to the world culture, the provision of support, the protection of foreign students. Migrants must be involved in the development of the culture and spiritual heritage of the people in the process of creating a new ethnic culture. Foster tolerant relationships in multicultural education. The main whole is the education of the person of culture; Creating conditions for the development and strengthening of diversity and variability within the culture itself. To develop in students certain skills and skills necessary in educational activity; To teach to mobilize their internal resources to change life and personality orientations. To build students 'self-confidence. Comprehensive language training using traditional methods and interactive techniques.

Students: Learn the language of the country of reception, have an oral and written speech. Improve the skills and skills of dialogue speech. Develop skills to engage in dialogue. Learn to work in a group, in a team. To build the relations of students with each other on the basis of respect, mutual understanding, arousing mutual interest in the national culture of the other people. Creatively, without violence, resolve emerging differences and conflicts. To study the culture of their people and the culture, national customs and traditions of other peoples. Prepare for future professional life through public and professional knowledge based on modern interactive technologies and learning practices.

Parents: Maintain close communication with the curator of the academic group of foreign students, teachers of the university. Take part in parental meetings, open days of the university, parental conferences, discussions, family evenings. Organize joint activities of parents and students. Introduce students to the culture and traditions of the holy people and the culture of the country of reception.

The work was carried out in accordance with the Competitive Growth Program of the Government of the Russian Federation of Kazan Federal University.

\section{Limitation and Study Forward}

This study was conducted on foreign students in Russia and Kazakhstan. However, this study can be done worldwide to obtain more accurate and general results.

\section{ACKNOWLEDGEMENTS}

The work is performed according to the Russian Government Program of Competitive Growth of Kazan Federal University.

\section{REFERENCES}

Akhtarieva, R. F., Ibragimova, E. R., \& Puchinina, O. P. (2019). Dynamics of formation of future teachers' professional intercultural competence among foreign students. Periodico Tche Quimica, 16(33), 423433.

Antipiev, A. G. (2009). The sociocultural factor and its significance in crisis Russian society. Pitirim Aleksandrovich Sorokin and modern problems of sociology: Materials of the International Scientific Conference, pp. 175-182.

Bąk, T., Kardis, M., Valco, M., Kalimullin, A. M., \& Galushkin, A.A (2019). A philosophical-sociological diagnosis of youth subcultures in the context of social changes. XLinguae, 12(2), 163-185. https://doi.org/10.18355/XL.2019.12.02.14 
Balashov, T. I. (2006). Practical psychology. Psychodiagnostics of relations between parents and children. Science, pp. 76-85.

Banks, J. (1996). Multicultural education: goals and dimensions. New values of education: the cultural and multicultural environment of schools. Innovator, 4, 15-19.

Bayanova, A. R., Vodenko, K. V., Sizova, Zh. M., Chistyakov, A. A., Prokopiev, A. I., \& Vasbieva, D. G. (2019). A philosophical view of organizational culture in contemporary universities. European Journal of Science and Theology, 15(3), 121-131.

Beregovaya, O. A., Lopatina, S. S., \& Oturgasheva, N. V. (2019). Barriers of social and cultural adaptation of foreign students in Russian universities. Perspektivy Nauki i Obrazovania, 38(2), 108-118. https://doi.org/10.32744/pse.2019.2.9

Bondarenko, D. M., Demintseva, E. B., Kavykin, O. I., Sledzevsky, I. V., \& Khalturina, D.A. (2007). Education as a factor in establishing in society the norms of ethno-confessional tolerance in the context of globalization (for example, Russia, France and Tanzania). History and modernity, 2, 35-48.

Bondarevskaya, E. V. (1999). Pedagogy: personality in humanistic theories and education systems. Rostov on Don: Creative Center "Teacher".

Bondyreva, S. K. (2011). Tolerance. Introduction to the problem. Moscow: Psychological and Social University.

Chubko, N., Morris, J. E., McKinnon, D. H., Slater, E. V., \& Lummis, G.W. (2019). SOLO taxonomy as EFL students' disciplinary literacy evaluation tool in technology-enhanced integrated astronomy course. Language Testing in Asia, 9(1), 234-252. https://doi.org/10.1186/s40468-019-0095-6

Dyuzhakova, M. V. (2008). The development of teacher education in a multicultural society. Voronezh: Voronezh State Pedagogical University.

Fetiskin N. P., Kozlov, V. V., \& Manuylov, G. M. (2002). Socio-psychological diagnosis of the development of personality and small groups. Retrieved from http://umc38.ru/wp-content/uploads/2016/02/FetiskinN.P.-Sotsialno-psihologicheskaya-diagnostika-razvitiya-lichnosti-i-malyh-grupp.pdf

Gorbunov, M. A., Fadeeva, A. V., Shirshikov, V. B., Matveev, P. A., Popova, O. V., Mitrofanova, M. Yu., Bakaeva, J. Yu., \& Mashkin, N. A. (2019). Nature protection potential of wildlife sanctuary: Protection and Preservation of its Ecological Biodiversity. Ekoloji, 107, 5033-5037, Article No: e107576

Gukalenko, O. V. (2003). Multicultural education: theory and practice. Russian Academy of Education, 1, 2324.

Gvarliani, T. E., Vidishcheva, E. V., \& Rassolov, I. M. (2015). The development of agriculture and trade relations in the Caucasus in the early 20th century. Bylye Gody, 38(4), 1039-1046.

Jarica, L. I. (1977). Theoretical Foundations of an Accelerated English Language Learning Course by the Method of "Immersion". Intensive Teaching Methods of Foreign Languages, 1, 56-68.

Kamalova, L. A. (2015). Formation of Professional Competences of "Primary Education" Profile Students While the Studying Process at the University. Review of European Studies, 7(1), 94-100. https://doi.org/10.5539/res.v7n1p94

Khairullina, E. R., Shubovich, M. M., Bogdanova, V. I., Slepneva, E. V., Mashkin, N. A., \& Rodyukova, T. N. (2020). Modern student youth civic identity: Political activity or social responsibility? Opcion, 36(Special Edition 27), 1703-1717.

Kim, T.-Y., Kim, Y., \& Kim, J.-Y. (2019). Role of Resilience in (De) Motivation and Second Language Proficiency: Cases of Korean Elementary School Students. Journal of Psycholinguistic Research, 48(2), 371-389. https://doi.org/10.1007/s10936-018-9609-0 
Kozlovtseva, N. A., \& Tolstova, N. N. (2019). Formation of the image of the russian world as an aspect of sociocultural adaptation of foreigners in the process of teaching. The Russian language. Bakhtiniana, 14(1), 82-110. https://doi.org/10.1590/2176-457338362

Kurkimbayeva, A. M., Akhatova, B. A., Gumovskaya, G. N., Kotenyatkina, I. B., \& Khuziakhmetov, A. N. (2020). Communicative Strategies in Modern Linguistics (on the Material of English Travel Blogs). XLinguae, 13(2), 33-49. https://doi.org/10.18355/XL.2020.13.02.03

Masalimova, A. R., Sangadzhiev, B. V., Shagieva, R. V., Gurbanov, R. A., \& Zhdanov, S. P. (2018). Philosophical and socio-psychological meaning of the concept of psycho violence in learning environment. XLinguae, 11(1), 126-135. https://doi.org/10.18355/XL.2018.11.01.12

Meng, Q. Z., Zhu, C., \&Cao, C. C. (2018). Chinese international students' social connectedness, social and academic adaptation: the mediating role of global competence. Higher Education, 75(1), 131-147. https://doi.org/10.1007/s10734-017-0129-x

Nieto, S. (1996). Affirming Diversity. White Plains. London: Longman Publishers.

Palatkina, G. V. (2001). Problems of multicultural educational space. Pedagogical problems of the formation of subjectivity of a schoolboy, student, teacher in the system of continuing education: a collection of scientific and methodological works. Moscow: Academy.

Pocebut, L. G. (2005). Mutual understanding of cultures. Methodology and methods of ethnic and crosscultural psychology. Psychology of Interethnic Tolerance. St. Petersburg: Publishing House St. Petersburg. Univ.

Santillan, J. P., Martin, J. T., Santos, M. E., \& Yambao, L. L. (2018). International students' cultural adaptation in the Philippines. Asian EFL Journal, 20(12), 234-252.

Sherina, E. A. (2013). Effective technologies for teaching Russian as a foreign language at a technical university (as exemplified by academic exchange groups). Basic research, 4(4), 1011-1014.

Slastenin, V. A., Isaev, I. F., Mishchenko, A. I., \& Shiyanov, E. N. (2002). Pedagogy. Moscow: School Press.

Yankovsky, L. V. (2005). Questionnaire of personality adaptation to a new cultural environment. Penza: Penza State Pedagogical University named after V.G. Belinsky.

Zasipkin, V. P., Zborowski, G. E., \& Shuklina, E. A. (2012). Problems of education and social integration of migrant children in the figures and dialogues. Khanty-Mansiysk: Publishing House "News of Ugra".

Zhou, J., Zhao, K., \& Dawson, P. (2020). How first-year students perceive and experience assessment of academic literacies. Assessment and Evaluation in Higher Education, 45(2), 266-278. https://doi.org/10.1080/02602938.2019.1637513

Zyubina, I. A., Dzyubenko, A. I., Borisenko, V. A., Popova, O. V., \& Prokopyev, A. I. (2019) Implicit Linguopragmatic strategies of speech behavior of English-speaking prosecutors. XLinguae, 12(4), 92102. https://doi.org/10.18355/XL.2019.12.04.08

Correspondence: Lera A. Kamalova, PhD in Education, Associate Professor of the Institute of Psychology and Education, Kazan (Volga region) University, Kazan, Russia. E-mail: leraax57@mail.ru 